\title{
Duolingo: An Arabic Speaking Skills' Learning Platform for Andragogy Education
}

\author{
Mahyudin Ritonga $\left(\mathbb{D},{ }^{1}\right.$ Suci Ramadhanti Febriani ${ }^{D},{ }^{2}$ Martin Kustati $\left(\mathbb{D},{ }^{2}\right.$ Ehsan Khaef $\left(\mathbb{D},{ }^{3}\right.$ \\ Apri Wardana Ritonga $\mathbb{D}^{4},{ }^{4}$ and Renti Yasmar $\mathbb{D}^{5}$
}

${ }^{1}$ Muhammadiyah University of West Sumatera, Padang, Indonesia

${ }^{2}$ Islamic State University of Imam Bonjol Padang, Padang, Indonesia

${ }^{3}$ Department of English Language, Islamic Azad University, Fasa, Iran

${ }^{4}$ Universitas Islam Negeri Maulana Malik Ibrahim Malang, Malang, Indonesia

${ }^{5}$ Institute Agama Islam Negeri Curup, Bengkulu, Indonesia

Correspondence should be addressed to Ehsan Khaef; ehsankhaef2006@gmail.com

Received 17 January 2022; Revised 2 February 2022; Accepted 4 February 2022; Published 25 February 2022

Academic Editor: Ehsan Namaziandost

Copyright ( 92022 Mahyudin Ritonga et al. This is an open access article distributed under the Creative Commons Attribution License, which permits unrestricted use, distribution, and reproduction in any medium, provided the original work is properly cited.

\begin{abstract}
Arabic communication skills for non-Arabs are faced with serious problems; therefore, the use of technology-based platforms is considered following students' wishes in the era of digital technology. Various technological devices have been widely used by educators for multiple levels of education but have not obtained maximum results. The novelty of this research is the use of Duolingo as a platform for teaching Arabic language skills. This study describes that Duolingo is very relevant to be used as a medium for learning Arabic for beginners because the teaching material begins with the new alphabet and vocabulary equipped with pictures. However, Duolingo still needs to make an essential revolution for learning Arabic speaking skills, especially for andragogy learners who have expert Arabic skills. Based on the findings, some implications are put forward.
\end{abstract}

\section{Introduction}

Speaking learning in the digital era is very challenging. The internet has greatly influenced the process of learning foreign languages in the past 20 years [1]. This is marked by the acceleration of technology and media, giving new language learning innovations [2]. Online education makes learning possible for wider audiences $[3,4]$. Specifically, technology can develop methods for acquiring language through three main elements of language: vocabulary, sound elements, and structure and construct for productive skills such as speaking and writing skills.

Limitations of distance and time cannot be a significant obstacle in obtaining language elements as it is known that foreign language skills are needed in the 21st century [5]. This shows that 21st-century skills are the ability to communicate, collaborate, and think critically and creatively [6]. The ability to communicate, especially in foreign languages, is one important element in facing the challenges of learning in the 21st century [7]. However, online media can deliver material in speaking learning as a form of obtaining concrete Arabic. One of the applications is Duolingo. It can also provide learners with new vocabulary absorption and structure [8]. So, this application becomes an option in foreign language learning.

Most distance learning systems use application platforms [9]. Duolingo platform is supported by the fact that beginner learners may efficiently use computer-assisted language learning tools to foster their foreign language study. The other research explains that the Duolingo platform effectively teaches seventh-grade students' vocabulary [10]. It is a web-based language learning platform and uses digital-based capabilities [11]. Nonetheless, they have to know which tool can better accelerate their purpose [12]. Duolingo's contribution can make learning easier for language learners or instructors when there are limited distance 
and time [13]. It is also applied in learning descriptive text which can help the students in the learning process [14]. Through electronic media intermediaries, teacher and student interactions can optimally perform the learning process [15].

However, andragogy education is education for adult levels [16]. The learning process of andragogy also emphasizes cognitive aspects as the basis for acquiring new vocabulary in learning foreign languages for speaking skills' capabilities [17]. In addition, andragogy education requires a structured learning environment, an assessment that is encouraged, and a strong motivation of the learners and instructors themselves [18].

The andragogy approach demands a conducive atmosphere [19]. Learners must get a sense of comfort in the learning situation. The development of the autonomy of each learning participant makes the learning conducive to learning participants. This is part of the characteristics of learning with the andragogy approach. In the principle of andragogy, students have the discretion to determine agreement in the learning process so that students feel that learning is conducive and that learning objectives are achieved because students generate interest in education. This follows the constructivism theory that builds independence in thinking and exploring knowledge [20].

The connection with foreign language learning andragogy education has a specific purpose, such as learning Arabic to understand the Qur'an and other Islamic sources, communication, and other vital aspects. These specific objectives should be sufficiently operational and straightforward to be used as a basis for determining the types of tests that will be used to determine the extent to which the desired objectives can be achieved.

Based on previous research, it is known that studies on language acquisition and language learning through media and applications have been carried out, such as using YouTube in learning foreign languages [21], using Edmodo media as a form of improving the quality of students' writing skills [22], using videos in improving various foreign language skills [23], using Instagram in learning Arabic [24], and using social media to learn foreign languages [25]. The other findings report that learners focus on formal learning and can use various online learning platforms [26]. Related to the previous research, the research on optimizing Duolingo for speaking skills in the level of adult learners has not been studied deeply.

\section{Literature Review}

Students' learning is supported by using information and communication technology as coordinating instruments, which might contain components of assessment, mentoring, and teaching, among other things. There are many different applications and procedures involved, such as web-based learning, computer-based learning, online classes, learning environments, and digital collaboration and group work. Incorporated into this is the delivery of content through a wide variety of digital media (e.g., the internet, intranet/ extranet, audio- and videotapes, satellite broadcasts, and interactive television) as well as access to resources that notify students of innovative ideas, which they can then portray on and incorporate into their current information. In cooperative learning techniques, where participants are urged to establish shared meaning and work as teams rather than competing against one another toward a common objective, computers may be utilized to facilitate cooperative learning [27]. Communication, information availability, material creation, and collaboration are all enhanced by using social media and social application programs such as for weblogs (blogs) and wikis. When integrated into curriculum design, the proper use of technology is intended to aid in the creation of new instructional strategies as well as the enhancement and enrichment of learning experiences for students. E-learning (also known as electronic learning) and "digital learning" are other terms for this kind of learning [28].

The term technology-enhanced learning (TEL) is used to denote the use of technology in the process of teaching and learning in the classroom. It is a broad term that is not decipherable, but it is reshaping education and educational institutions in ways that are difficult to comprehend or predict. This means that it is tough to overlook [29].

In a nutshell, technology-enhanced learning (TEL) refers to any technology that improves the learning process. Historically, the phrase has been used to refer to both analog and digital innovations, but in recent decades, we have seen that digital TEL is increasingly dominating over education in various forms of instructional software. TEL is altering and strengthening teaching and educational institutions to the extent that it is difficult to comprehend [30]. This means that it is almost challenging to deny! This is particularly true in light of the increasing prominence of education applications, teacher-training software, and online learning programs. The field of education is approaching a period in which technology is no longer merely an excellent resource but is also a crucial instrument in enhancing the experience for both learners and lecturers.

There are several reasons why technology-enhanced learning is crucial. It is prominent not only because it is the quality of education demanded today but also because it can enhance educational outcomes. In the preceding paragraphs, we discussed how mobile applications (apps), software, and e-learning tools are some of the most essential and, in many cases, irreplaceable resources available to educators. In recent years, students have grown more technologically literate than ever before, and a significant portion of their day is spent dealing with some sort of technology [31]. Because of the simplicity with which they handle technology and their comfortability, children today anticipate and thrive when dealing with technology in a culture that is becoming more and more dominated by ever-developing smartphones, tablets, laptops, and other devices of all kinds. Educators may take advantage of this growing technological device by incorporating technology into their classrooms and lectures to promote connection, participation, and knowledge.

The learning theories of behaviorism, cognitivism, and constructivism are the three most prevalent learning theories that have directed education and educational improvement 
throughout history [32]. Behaviorism views learning as a process that happens whenever an adequate observable execution of behavior occurs due to an accompanying stimulus. The reinforcement of the stimulus-response relationship contributes to the ongoing development of the desirable behavior. When teachers and psychologists began to become interested in the mental functions related to knowledge acquisition, organization, preservation, and retrieval in the 1950s, they moved their attention to cognitivism $[32,33]$. In both behaviorism and cognitivism, the underlying assumption is that an actual word exists independently of the student and is objectively true. Constructivism holds that learning occurs due to personal understanding of real-world situations in which we participate. Knowledge is not considered independent of the student; rather, students are seen as creating meaning rather than getting it [32].

More importantly, learning contexts have substantially transformed into sophisticated, versatile, and technologically advanced contexts [34]. Examples include integrating course-/module-oriented features with administrative, managerial, and social resources in a sophisticated architecture connected with third-party applications. This crossdomain, quick, and intense growth necessitates the deconstruction of the educational theories/models that serve as the foundation for guiding learners and understanding their behavior. During investigating this study subject, two explanations are discovered in the literature. There are two types of arguments against theories. The first is the antitheory debate, which holds that theories are false since convenient theories cannot describe the learning process [35]. The second argument used in this study asserts that learning theories are a vital ingredient of teaching and learning since they are inextricably linked to any effective instructional design [36]. Because TEL artifacts are more than just means for delivering information to consumers, learning theories are fundamental in this setting, as in many other fields. They are giving ways for students to generate knowledge and develop new cognitive structures inside their minds. As a result, it is necessary to examine these artifacts from this point of view.

Since learning is the mechanism through which behavioral change and information, abilities, and perspectives are gained, a learning theory, or a mixture of learning theories, is forced to justify it [37]. This is true at both practical and theoretical levels; for example, information processing theory incorporates behaviorist and cognitive theories [38]. [39]. Specifically, this study explores learning theories that impact learning and provides explanations for the mechanisms through which that effect occurs. Because e-learning theories coincide with other ideas, such as human-computer interaction [40], it is impossible to distinguish between them.

CALL is a term often used to refer to the use of the internet or technology (computer-assisted language learning). Following [41], it is a strategy to learn and teach foreign languages that use computers and computer-based resources such as the internet to deliver, consolidate, and evaluate content to be introduced to improve student performance.
In addition, mobile devices are becoming more popular for accessing the internet these days [42]. Another term, MALL (mobile-assisted language learning), has started to describe a method of providing autonomous and successful language learning. As the use of smartphones to assist learning becomes more popular, Kukulska-Hulme and Shield [43] described MALL as an access point to a wireless device network, which will connect with such networks as the use of mobile devices to promote learning increases. MALL is concerned with applying mobile technologies in the context of language learning [44]. As mobile technology advances, it opens up new avenues for enhancing students' learning experiences at all levels of school, regardless of their location. It may make it easier for students to have access to educational materials without being physically present in the workplace. When it comes to accessing the most current occurrences in the classroom, mobile devices are an excellent tool $[42,45]$.

There are a plethora of apps available for learning English. Duolingo is an example of a technology-based program that has gained widespread popularity. "Duolingo," a language-learning program available on the Wikipedia website, takes a data-driven approach to teaching. At each stage of the process, the system evaluates which questions the consumers have difficulty answering and what sorts of errors they make. Afterward, it collects the data and learns from the patterns that it detects. Young learners who wish to learn English via practical and entertaining applications may use Duolingo to improve their English language skills [42]. Duolingo is a free online language learning tool developed to make learning the English language easier. Practice is vital for students to acquire English abilities, and exercise is particularly significant since it is designed to serve as a tool for testing and evaluating learners' capacity to achieve the content assigned to them. It is essential to consider if the activities are appropriate to the situation when doing exercises. The activities in spoken vocabulary given in the Duolingo Free Language Learning Application are of particular interest to the researcher [42].

Users may practice whenever and wherever they want with the Duolingo Free Language Learning Application, which can be downloaded on their mobile phone or PC/ laptop. Duolingo employs a game principle technique to motivate students to continue their studies. It is constructed like a computer game, with the players required to complete various stages. After a student has mastery of the prior content or level, the subsequent lessons are accessible. Exercise options include multiple choice, writing, and speaking via a microphone. Participants may complete a range of sorts of exercises [42].

Duolingo purposefully introduced the notion of play and learned to make everyone feel more comfortable and more straightforward to utilize the service. We have all felt exhausted from our everyday routines, and for a little while, we will be able to rest while learning a new language. The research is intended to provide easiness to learners of English through the use of multimedia learning applications such as Duolingo, which can be used to practice independently and can be used anywhere, including places of study, 
courses, schools, homes, and other areas of public accommodation and transportation.

\section{Method}

The approach used in this research is analytical descriptive, which examines the phenomena of Arabic learning resource media to solve actual problems by collecting data, classifying them, analyzing, and interpreting the data. The descriptive analysis method is carried out by describing the facts, followed by analysis, not merely describing but also providing sufficient understanding and explanation of the content of the Duolingo application as a learning medium to improve one's Arabic speaking skills. The method used in this paper is a library research method with data sources obtained from the Duolingo application as the primary source, scientific articles related to Duolingo, scientific reports, and the pieces of information from the internet related to this topic. The collected data are then analyzed by classifying, analyzing, and interpreting them. This way, the results of this research can be presented in detail and systematically into a scientific report for those in need.

\section{Results and Discussion}

4.1. Description of Duolingo and Using for Arabic Learning. Duolingo is a digital platform widely used by new language learners [46]. Duolingo has an exciting and fun feature for its users, namely, "gamified," wherein there is a combination of audio and video about Arabic grammar designed in the form of a game [47]. With this combined audio-visual feature, Duolingo users can learn Arabic while playing. This makes it easy for Arabic learners because users of the Duolingo application can learn in a relaxed, fun, and not dull way when learning Arabic using this platform [48].

Duolingo users appreciate the "gamified" design, which is interactive and interesting to try [3]; besides being free, the Duolingo application also provides clear information to bring convenience to users [49]. The gamification elements contained in Duolingo are perceived positively to provide learning motivation for users; not only that, but the gamification feature also requires application users to be actively involved in game-based learning. In addition, users of this application respond positively to the feedback feature on every activity and error contained in the application when used [45].

Based on the appearance of the application, it is described that Duolingo can be used to promote two foreign languages simultaneously [50], but each language material has its own limitations. Duolingo is very relevant for beginner to intermediate level language learners but is not recommended for higher needs because Duolingo prefers the direct translation method as Garcia's illustration explains that users of the Duolingo application often find ambiguity in the results of Duolingo's translation because this application will translate every word literally [44]. As a result, new language learners feel confused in determining the vocabulary translated by Duolingo even though they have learned the new vocabulary in the application. Not only this, some of the terminologies in the Duolingo application are not equipped with images or other visual media, so this makes it difficult for new language learners to memorize vocabulary through Duolingo [51].

Seeing the other side of Duolingo's limitations, users of this application are satisfied with accessing Duolingo to increase their knowledge of foreign language vocabulary [52], pronunciation and intonation, correct grammar, and inspirational image illustrations in vocabulary [53]. As an illustration, Vesselinov and Grego in Heba Bahjet compared foreign language acquisition for language learners using Duolingo with the classical method using a dictionary alone [46]. Language learners using Duolingo have the best and fastest foreign language improvement than language learners using only a dictionary [54]. Another illustration can be seen from the performance of the Duolingo application on the digital platform, which has been downloaded more than 100 million times, as many as 11 million people have provided reviews and received a rating of 4.8 out of 5 scales effective for improving language skills [55].

In Duolingo (Figure 1), users have to go through levels of learning. Starting from learning alphabet 1 to alphabet four which contains how to read Arabic letters, vowels, and intonation, users are also served with exercises and examples. The material continued learning about facilities at home, in the office, about bags, family, pictures, clothes, hobbies, and various foods. Uniquely, application users cannot change material if the previous material has not passed. However, Duolingo still needs a significant revolution to improve Arabic speaking skills for active Arabic speakers; it is highly recommended for beginners.

Duolingo proves that, with its help, it can encourage users to learn a second language [11] and even have the opportunity to try to learn a new language. In particular, learning Arabic speaking skills, Duolingo still needs to make a revolution to provide the best display for learners of this language. However, Duolingo is so confident that advanced students or learners of andragogy can easily use it. Through Duolingo, it encourages andragogy learners to learn independently by exploring directly to application sources without the help of a teacher. Duolingo is easily accessed anywhere and anytime, providing an excellent opportunity for users to practice foreign languages without any distractions [56].

Overall, foreign language learners using Duolingo gave positive comments and satisfaction in running this platform $[57,58]$. Some users claim that they are willing to be used as research samples on the usefulness of using this application, although there are users who find a saturation point when operating it because the level of material in this application is specifically for novice students [59]. Andragogy students with expert language skills will stop exploring this application, while beginner andragogy students will appear on the same level as other beginner foreign language learners.

4.2. Andragogy Applications in Learning Activities. The problems that often arise in education are student learning outcomes, outputs, and outcomes [60]. When students do 

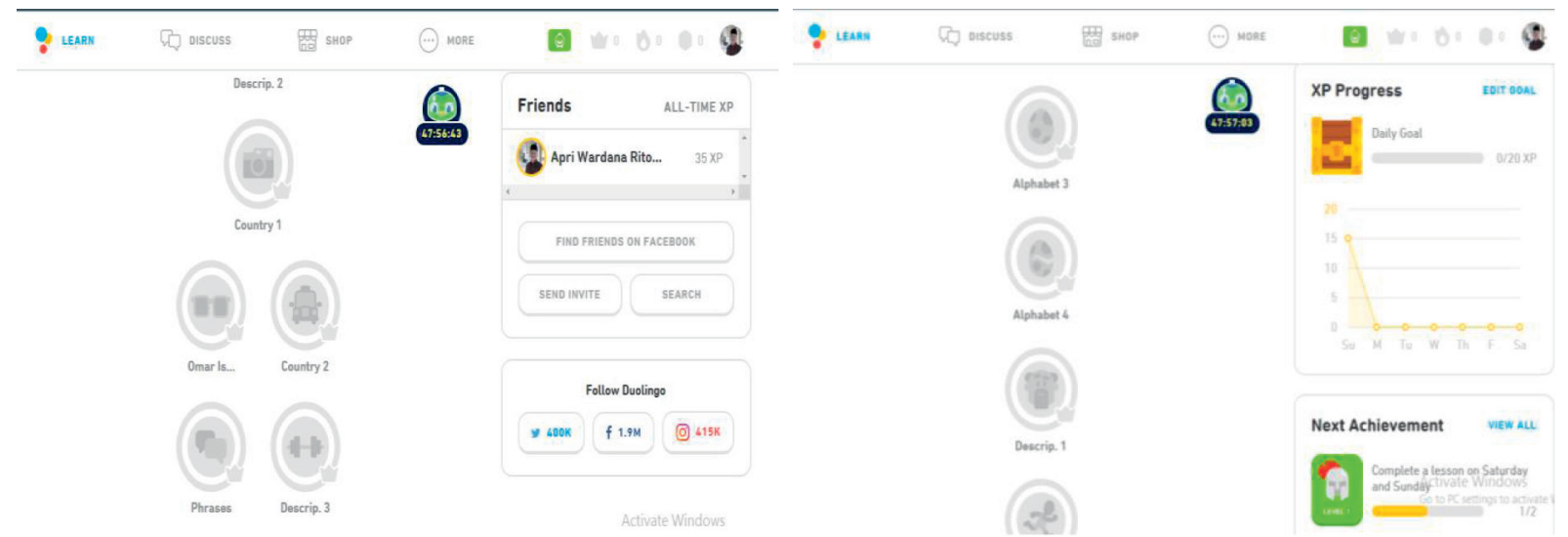

FIgURE 1: The environment of the Duolingo application.

not understand the subject matter in terms of cognitive, affective, or psychomotor, it indicates a learning process that is not following educational procedures. One of the causes of unsuccessful learning is learning methods that are not following the implementation procedures, and andragogy has not been applied optimally in the implementation of learning. Knowles in Henschke clearly stated that if a person learns to be 17 years old, using andragogy principles in his learning activities has become feasible [61]. This age is considered worthy of getting out of the children's learning model so that the learning methods used must also be distinguished.

The use of the Duolingo application as a medium for learning andragogy is considered appropriate in today's era because users can use it independently and without limitations of space and time. Andragogy learners can simultaneously explore and develop the learning media that are being used. This gives a positive value to the application user's self-development of analytical and critical skills for each learning material being studied [62]. Figure 2 illustrates that andragogy learners also play a role in providing critical thinking in the learning process both online and offline to find good learning outcomes.

Andragogy-based online learning to improve critical thinking skills, as shown in Figure 2, requires learners to be ready for all significant changes in the indicators of educational success undertaken [63]. The critical thinking andragogy learning model has a different appearance from the learning process in the classroom; this model carries the principle of a refreshing attitude that must be developed through the learning process [64], the evaluation process, assessment, assignment, and student-teacher interaction, and vice versa. Online-based andragogy learning needs to involve all of the above pillars proportionately and wisely. Mentors and students who take online classes can learn well and improve their critical thinking skills.

In addition, there are many differences in the learning models of adults and children. Adults can be taught to be more active if they feel involved in learning activities [65], mainly if they contribute thoughts and ideas that make them feel valued and have self-esteem in front of their friends. This means that adults will learn better if their personal opinions

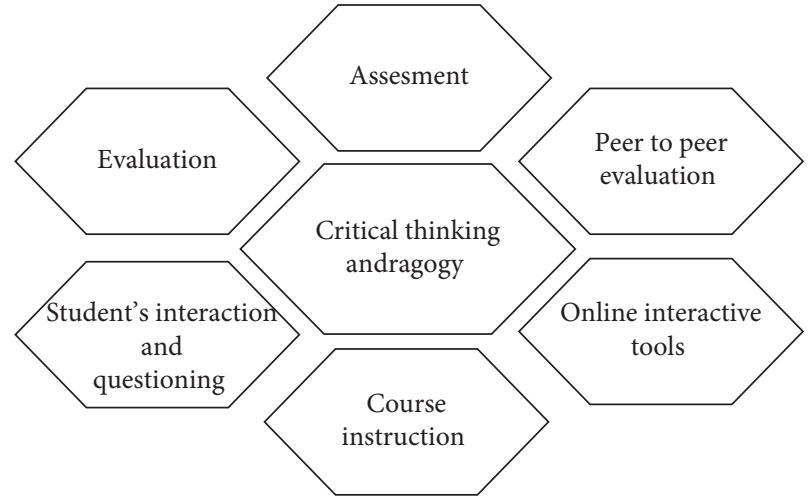

Figure 2: Critical thinking skills in andragogy.

are respected and will be happier if they contribute ideas and suggestions to the material being taught [66], rather than having to listen to the tutor's explanation continuously. Knowles analyzes differences in the learning process between adults and children because adults have six things: the self-concept, the role of the learner's experience, readiness to learn, orientation to learning, the need to know, and motivation [67].

These six things become the fundamental assumptions that support andragogy as an approach to formal and nonformal education. Andragogy is better known as "the art and science of helping an adult learn." [68] Understanding education is no longer just an effort to transmit knowledge but also effective shaping and developing skills as a lifelong learning process. As for children, their teaching and learning process must receive serious attention from both teachers and parents [69]. The difference between adult and child learning models is given in Table 1.

The children's learning model (pedagogy) has more effort to transmit several experiences and skills to prepare children to face opportunities and challenges in the future [70]. The substance of the transmission is based on the needs of learners that support their future success in life, while the adult learning model (andragogy), more oriented to selfdevelopment [71], guides them to find new knowledge, strengthen skills, and sharpen attitudes to solve the problems they face in life. If the learning model chosen is right with the 
TABLE 1: The differences in learning models for adults and children.

\begin{tabular}{|c|c|c|}
\hline Differentiating factor & Kids' learning style & Adult learning style \\
\hline Independent learning & Depend on others & Able to learn independently \\
\hline Life experience & Does not act as learning & Important to be a sou \\
\hline Readiness to learn & Depends on the teacher & Needs of life and work demands \\
\hline Learning orientation learning & The material becomes the main orientation & Oriented to self-skills \\
\hline Utilization of lear & Useful only for childhood only & Should be applied immediately \\
\hline Learning motivation & External factors are ver & Emerging from oneself \\
\hline Learn & Tend to be rigid and formal & Relaxed but focused \\
\hline Lear & Conducted by the teacher & Conducted by the facilitator \\
\hline $\begin{array}{l}\text { Formulation of learning } \\
\text { objectives }\end{array}$ & Always carried out by teachers only & $\begin{array}{c}\text { Conducted by facilitators and even training } \\
\text { participants }\end{array}$ \\
\hline Analysis of learning needs & Conducted by & Training participants who analyze learning needs \\
\hline Nature of teaching materials & $\begin{array}{l}\text { Very theoretical and arranged in a linear } \\
\text { manner }\end{array}$ & Theoretical, practical, and flexible as needed \\
\hline Learning evaluation & Conducted by the teacher & Conducted by the facilitator and training participants \\
\hline
\end{tabular}

learning, it will undoubtedly affect the learning outcomes. Duolingo can help good learning outcomes for beginner Arabic learners.

\section{Conclusion}

Online learning platforms such as Duolingo make it easy for users to access and discuss the subject matter without limited space and time. This research has implications for the Duolingo platform, which is very relevant for learning basic Arabic for novice learners because Duolingo starts teaching materials from the alphabet to the new vocabulary using pictures and visuals. However, the Duolingo application still needs to develop feature products to speak Arabic for expert Arabic learners. Andragogy learners are recommended to adopt Duolingo as a learning medium because it is equipped with language games that reduce boredom while learning. Duolingo opens up opportunities for users to learn a second language and learn more new languages. This research encourages future researchers to develop Duolingo applications, especially in the Arabic language aspect, in terms of vocabulary, sentence structure, and language skills, including listening, speaking, reading, and writing. This way, this application will be more helpful in preserving Arabic around the world through the Duolingo online platform.

Overall, because of TEL, instructors are no longer restricted to their respective universities' texts. Learners may study in various ways by utilizing a variety of materials such as video, audio, and interactive learning opportunities. Teachers can come up with innovative strategies to engage their pupils while teaching them. Technology has transformed the school environment, allowing students to engage in more hands-on activities. As a result of the availability of online resources for topic specialists and fellow instructors, a larger pool of materials is accessible anywhere on the internet. In addition, numerous online forums and discussion boards will debate how to effectively use particular tools and software in the classroom without technical challenges and more extended break-in periods.

From another perspective, e-learning may enable students to pick a number of modules to complete over a time of their choosing, with each module giving a variety of resources to choose from based on their learning preferences, as well as the option to decide how and when to be evaluated in each. On many levels, such a flexible framework looks impracticable, but with the growing number of online courses, free institutions, and the opportunity for peer assistance (social media). The problem for present higher education providers is deciding how much of this flexible offering to absorb and supply. The additional value of university education, with a structured curriculum leading to a clear and timely certification, is likely to remain the gold standard for some time. If institutions accept others' e-learning services, basically providing the means for authenticating evaluation and credit accumulation, the university college model might emerge again. Maintaining worldwide competitiveness and brand identification and managing this within various higher education pricing and finance regimes are likely to be the most challenging problem for universities over the next decade. Future shortto-medium-term repercussions for the three key stakeholders encompass:

(i) Students: taking greater responsibility for their learning and selecting and utilizing technologies that can enhance their knowledge with the guidance of their educators.

(ii) Instructors: identifying opportunities for flexibility in delivery, with an increased focus on controlling the learning process rather than being the primary supplier of learning materials.

(iii) Institutions: allowing for flexible systems, where students can register and choose learning options. When it comes to awarding credits and degrees, the responsibility of institutions shifts to that of providing mechanisms and structures, as well as the quality checks that are required.

The broader implications are that funders (government organizations) acknowledge alternative methods and offer support mechanisms-principally finance-to enable such advances to take place. Learners who want to pursue degrees outside the established degree frameworks will need flexible 
financing to achieve this mix of institutional and government structures and support to recognize flexible delivery and assessment. Flexibility is likely limited if there is no such assistance, with alternatives inside programs or modules remaining the primary emphasis.

In light of the significance and influence of utilizing the Duolingo program on teaching and learning in the classroom, the researcher proposes that schools at the high level offer instructors the option to get training to know how to utilize media in the school properly. Many different types of apps may be used in teaching and learning, which the instructor should present. It may also make it simpler and more enjoyable for pupils to learn English as a second language. In addition to theory, such as teaching techniques and instructional technology, the education institution or schools should focus on the learning activities for teachers. As a result, it can be stated that the use of the Duolingo program as a media technology in schools is something that should be considered.

The use of technology, such as the Duolingo application, may undoubtedly assist students in improving their English language abilities, particularly their speaking ability. As a result, instructors are urged to use this application within their language teaching and learning activities. On the contrary, instructors must ensure that this application can be utilized successfully by their students. The usage of a mobile phone in the classroom is another significant factor since some schools restrict using a mobile phone during class time. On the contrary, this study is exclusively concerned with determining the efficacy of Duolingo in improving participants' communication abilities in a single situation. It is possible that future studies may examine the usage of Duolingo in other contexts or will include different schools and students. Another intriguing area to look into is the attitudes of instructors and learners on the use of Duolingo as a learning tool.

\section{Data Availability}

The data are available through direct contact with the corresponding author.

\section{Conflicts of Interest}

The authors declare that they have no conflicts of interest.

\section{References}

[1] J. Reinhardt, "Social media in second and foreign language teaching and learning: blogs, wikis, and social networking," Language Teaching, vol. 52, no. 1, pp. 1-39, 2019.

[2] A. Littlejohn, H. Beetham, and L. Mcgill, "Learning at the digital frontier: a review of digital literacies in theory and practice," Journal of Computer Assisted Learning, vol. 28, no. 6, pp. 547-556, 2012.

[3] P. Gadanecz, "The nature of positive emotions via online language learning," in Proceedings of the 2018 9th IEEE International Conference on Cognitive Infocommunications (CogInfoCom), pp. 197-204, CogInfoCom, Budapest, Hungary, August 2018.
[4] H. Khayrallah, J. Bremerman, A. D. McCarthy, K. Murray, W. Wu, and M. Post, "The JHU submission to the 2020 duolingo shared task on simultaneous translation and paraphrase for language education," in Proceedings of the Fourth Workshop on Neural Generation and Translation, pp. 188-197, Association for Computational Linguistics, Stroudsburg, PA,USA, January 2020.

[5] S. E. Saleh, "Critical thinking as a 21 st century skill: conceptions, implementation, and challenges in the EFL classroom," European Journal of Foreign Language Teaching, vol. 4, no. 1, pp. 1-16, 2019.

[6] S. R. Febriani, W. Wargadinata, S. Syuhadak, and F. M. A. Ibrahim, "Design of Arabic learning for senior high school in the 21st century," Jurnal Al-Bayan: Jurnal Jurusan Pendidikan Bahasa Arab, vol. 12, no. 1, pp. 1-21, 2020.

[7] A. Halverson, 21 St Century Skills and the '4Cs' in the English Language Classroom by Andy Halvorsen, American Institute Of English Language Pvt Ltd., University of Oregon, Eugene, Oregon, 2018.

[8] P. Munday, "Duolingo. Gamified learning through translation," Journal of Spanish Language Teaching, vol. 4, no. 2, pp. 194-198, 2017.

[9] T. Gonulal, "The use of instagram as a mobile-assisted language learning tool," Contemporary Educational Technology, vol. 10, no. 3, pp. 309-323, 2019.

[10] S. D. Matra, "Duolingo applications as vocabulary learning tools," JELLE: Journal Of English Literature, Linguistics, and Education, vol. 1, no. 1, pp. 46-52, 2020.

[11] O. Akbaş, "How to use duolingo effectively in second language learning ?: a currere essay," Journal of Teacher Education and Lifelong Learning (TELL), vol. 1, pp. 8-13, 2019, https://dergipark.org.tr/tr/pub/tell.

[12] I. Irham, “Assessing livemocha and duolingo evaluation tasks: adapting chapelle call assessment criteria in autonomous leaning experience," Erudio Journal of Educational Innovation, vol. 5, no. 1, pp. 103-114, 2018.

[13] A. Jaelani and D. R. Sutari, "Students' perception of using duolingo application as a media in learning vocabulary," The 2nd Bogor English Student and Teacher (BEST), vol. 2, no. 20, pp. 40-47, 2021.

[14] D. Ayu and A. Anggraeni, "The implementation of duolingo to teach descriptive text in scientific approach," PROJECT (Professional Journal of English Education), vol. 3, no. 6, p. 711, 2020.

[15] D. Broad, "Literature review of theories of second language acquisition," Journal of Applied Linguistics and Language Research, vol. 7, no. 1, pp. 80-86, 2020.

[16] N. A. Shumakova and M. V. Savelyeva, "Training technologies for Industry 4.0 experts: updated andragogical model," IOP Conference Series: Materials Science and Engineering, vol. 537, no. 4, pp. 042050-042055, 2019.

[17] J. S. Payne, "Developing L2 productive language skills online and the strategic use of instructional tools," Foreign Language Annals, vol. 53, no. 2, pp. 243-249, 2020.

[18] A. Youde, "Andragogy in blended learning contexts: effective tutoring of adult learners studying part-time, vocationally relevant degrees at a distance," International Journal of Lifelong Education, vol. 37, no. 2, pp. 255-272, 2018.

[19] M. Hasyim, "Andragogi dalam pembelajaran bahasa arab," ARABIYAT: Jurnal Pendidikan Bahasa Arab dan Kebahasaaraban, vol. 2, no. 1, pp. 31-42, 2015.

[20] S. Sutaman and S. R. Febriani, "Optimizing Arabic speaking skills based on integration of learning theory framework in 
higher education," Arabiyat: Jurnal Pendidikan Bahasa Arab dan Kebahasaaraban, vol. 8, no. 1, pp. 75-89, 2021.

[21] V. Li, "Social media in English language teaching and learning," International Journal of Learning and Teaching, vol. 3, 2017.

[22] Y. W. Lam, K. F. Hew, and K. F. Chiu, "Improving argumentative writing: effects of a blended learning approach and gamification," Language, Learning and Technology, vol. 22, no. 1, pp. 97-118, 2018.

[23] C. Oddone, "Using videos from YouTube and websites in the CLIL classroom," Studies about Languages, vol. 18, 2011.

[24] M. A. AlGhamdi, "Arabic learners' preferences for instagram English lessons," English Language Teaching, vol. 11, no. 8, p. 103, 2018.

[25] S. R. Febriani, "Implementation of Arabic learning during COVID-19 emergency in Indonesia: HOTS, MOTS, or LOTS?” Alsinatuna, vol. 5, no. 2, pp. 117-129, 2020.

[26] I. Grace and Nageswari, "Advantages of mobile gamification in learning English language," Turkish Journal of Computer and Mathematics Education, vol. 12, no. 6, pp. 4212-4218, 2021.

[27] R. M. Abobaker, S. Elsayed Khalil, M. Mubarak Merghani, A. Mahadeen, E. G. Abdelraheem, and A. M. HamdanMansour, "E-learning success factors from the perspective of academic staff at nursing and education colleges during COVID-19 pandemic: a comparative study," Educational Sciences: Theory and Practice, vol. 21, no. 3, pp. 1-10, 2021.

[28] A. A. A. Ahmed and A. Ganapathy, "Creation of automated content with embedded artificial intelligence: a study on learning management system for educational entrepreneurship," Academy of Entrepreneurship Journal, vol. 27, no. 3, pp. 1-10, 2021.

[29] A. A. Alkhaldi, "ESL Materials selection: key principles and suggestions," Educational Sciences: Theory and Practice, vol. 21, no. 3, pp. 12-26, 2021.

[30] A. Gunasinghe, J. A. Hamid, A. Khatibi, and S. M. F. Azam, "The viability of UTAUT-3 in understanding the lecturer's acceptance and use of virtual learning environments," International Journal of Technology Enhanced Learning, vol. 12, no. 4, pp. 458-481, 2020.

[31] K. Seneviratne, J. A. Hamid, A. Khatibi, F. Azam, and S. Sudasinghe, "Multi-faceted professional development designs for science teachers' self-efficacy for inquiry-based teaching: a critical review," Universal Journal of Educational Research, vol. 7, no. 7, pp. 1595-1611, 2019.

[32] P. A. Ertmer and T. J. Newby, "Behaviorism, cognitivism, constructivism: comparing critical features from an instructional design perspective," Performance Improvement Quarterly, vol. 26, no. 2, pp. 43-71, 2013.

[33] S. V. Vadivu and S. Chupradit, "Psychosocial and occupational impact assessment due to internet addiction: a critical review," Systematic Reviews in Pharmacy, vol. 11, no. 7, pp. 152-155, 2020.

[34] R. Hammad, M. Odeh, and Z. Khan, "Towards a generalised e-learning business process model," in Proceedings of the Seventh International Conference on Business Intelligence and Technology-BUSTECH, pp. 20-28, Athens, Greece, 2017.

[35] A. Kolb and D. Kolb, "Experiential learning theory: a dynamic, holistic approach to management learning, education and development," in The SAGE Handbook of Management Learning, Education and Development, S. Armstrong and C. Fukami, Eds., pp. 42-68, SAGE Publication, London, UK, 2009.
[36] D. H. Schunk, Learning Theories: An Educational Perspective, Pearson, London, UK, 2012.

[37] V. Singh and A. Thurman, "How many ways can we define online learning? A systematic literature review of definitions of online learning (1988-2018)," American Journal of Distance Education, vol. 33, no. 4, pp. 289-306, 2019.

[38] E. Pratiwi, T. Nusantara, S. Susiswo, M. Muksar, and S. Subanji, "Characteristics of students' cognitive conflict in solving a problem based on information processing theory," International Journal of Learning, Teaching and Educational Research, vol. 18, no. 2, pp. 76-88, 2019.

[39] M. Knowles, E. Holton, and R. Swanson, The Adult Learner: The Definitive Classic in Adult Education and Human Resource Development, Routledge, London, UK, 2015.

[40] P. Deshwal, A. Trivedi, and H. L. N. Himanshi, "Online learning experience scale validation and its impact on learners' satisfaction," Procedia Computer Science, vol. 112, pp. 2455-2462, 2017.

[41] M. Warschauer, "Computer assisted language learning: an introduction," in Multimedia Language Teaching Tokyo: Logos International, S. Fotos, Ed., pp. 3-20, 1996.

[42] Hafifah, "The effectiveness of duolingo in improving students' speaking skill at madrasah aliyah bilingual batu school year 2019/2020," Thesis, English Education Department, Postgraduate Program, Islamic University of Malang, Malang, Indonesia, 2020.

[43] A. Kukulska-Hulme and L. Shield, "An overview of mobile assisted language learning: from content delivery to supported collaboration and interaction," ReCALL, vol. 20, no. 3, pp. 271-289, 2008.

[44] T. Miangah and A. Nezarat, "Mobile-assisted language learning," International Journal of Distributed and Parallel Systems (IJDPS), vol. 3, no. 1, pp. 309-319, 2012.

[45] M. Calimag and Conde, "Ubiquitous learning environment using android mobile application," International Journal of Renewable Energy Technology, vol. 2, no. 2, pp. 119-128, 2014.

[46] I. Garcia, "Learning a language for free while translating the web. does duolingo work?" International Journal of English Linguistics, vol. 3, no. 1, pp. 19-25, 2013.

[47] M. Shortt, S. Tilak, I. Kuznetcova, B. Martens, and B. Akinkuolie, "Gamification in mobile-assisted language learning: a systematic review of duolingo literature from public release of 2012 to early 2020," Computer Assisted Language Learning, pp. 1-38, 2021.

[48] H. Ahmed, "Duolingo as a bilingual learning app: a case study," Arab World English Journal, vol. 7, no. 2, pp. 255-267, 2016.

[49] S. Loewen, D. Crowther, D. R. Isbell et al., "Mobile-assisted language learning: a Duolingo case study," ReCALL, vol. 31, no. 3, pp. 293-311, 2019.

[50] C. H. Karjo and W. Andreani, "Learning foreign languages with duolingo and memrise," Proceedings of the 2018 International Conference on Distance Education and Learning, vol. 45, pp. 109-112, 2018.

[51] S. Savvani, "State-of-the-art duolingo features and applications," The Challenges of the Digital Transformation in Education, vol. 917, pp. 139-148, 2019.

[52] A. D. Tiara, M. A. Rahman, and C. Handrianto, "The Students' perception about use of duolingo application for improving English vocabulary," International Journal of Education and Information Technologies, vol. 4, no. 4, pp. 690701, 2021. 
[53] M. Khaira, "The effectiveness of crossword puzzle in improving mufradat skills," Tanwir Arabiyyah: Arabic As Foreign Language Journal, vol. 1, no. 2, pp. 55-62, 2021.

[54] E. Şendurur, E. Efendioğlu, N. Y. Çalişkan, N. Boldbaatar, E. Kandin, and S. Namazli, "The M-learning experience of language learners in informal settings," in Proceedings of the 13th International Conference on Mobile Learning, pp. 119123, April 2017, http://www.iadisportal.org.

[55] A. Irawan, A. Wilson, and S. Sutrisno, "The implementation of duolingo mobile application in English vocabulary learning," Scope: Journal of English Language Teaching, vol. 5, no. 1, p. 8, 2020.

[56] K. R. Finardi, R. G. Leao, and G. B. Amorim, "Mobile assisted language learning: affordances and limitations of duolingo," Education and Linguistics Research, vol. 2, no. 2, p. 48, 2016.

[57] L. Carvalho and L. Oliveira, "Emotional design in web interfaces," Observatorio, vol. 11, no. 2, pp. 14-34, 2017.

[58] K. K. James and R. E. Mayer, "Learning a second language by playing a game," Applied Cognitive Psychology, vol. 33, no. 4, pp. 669-674, 2019.

[59] U. N. Nadhifah and D. Puspitasari, "Learning English through duolingo: narrating students' experience during covid-19 pandemic time," Ethical Lingua: Journal of Language Teaching and Literature, vol. 8, no. 1, pp. 302-310, 2021.

[60] L. Lassnigg, "'Lost in translation': learning outcomes and the governance of education," Journal of Education and Work, vol. 25, no. 3, pp. 299-330, 2012.

[61] J. A. Henschke, "Considerations regarding the future of andragogy," Adult Learning, vol. 22, no. 1, pp. 34-37, 2011.

[62] T. Karsenti, O. M. Kozarenko, O. Kozarenko, and V. Skakunova, "Digital technologies in teaching and learning foreign languages: pedagogical strategies and teachers' professional competence," Education \& Self Development, vol. 15, no. 3, pp. 76-88, 2020.

[63] S. Kaddoura and F. Al Husseiny, "On-line learning on information security based on critical thinking andragogy," World Transactions on Engineering and Technology Education, vol. 19, no. 2, pp. 157-162, 2021.

[64] G. Maudsley and J. Strivens, "Promoting professional knowledge, experiential learning and critical thinking for medical students," Medical Education, vol. 34, no. 7, pp. 535-544, 2000.

[65] K. Moore and M. Shemberger, "Mass communication andragogy for teaching online adult learners," AEJMC, vol. 9, no. 1, pp. 35-40, 2019, http://www.aejmc.us/spig/journal.

[66] O. H. Aljohani and S. M. Alajlan, "The application of andragogy for the advanced diploma program in education at Saudi arabia's taif university," International Journal of Information and Communication Technology Education, vol. 17, no. 3, pp. 1-11, 2021.

[67] M. Knowles, The Adult Learning, Gulf Publishing Company, London, UK, 3rd edition, 1979.

[68] M. G. Efgivia, F. Zhahiriyah, M. Widiyanti, and E. Iskandar, "Implementation of andragogy theory in Arabic learning class XII at islamic senior high school azzhahiriyah," Advances in Social Science, Education and Humanities Research, vol. 585, pp. 188-193, 2021.

[69] J. J. McNally, P. Piperopoulos, D. H. B. Welsh, T. Mengel, M. Tantawy, and N. Papageorgiadis, "From pedagogy to andragogy: assessing the impact of social entrepreneurship course syllabi on the millennial learner," Journal of Small Business Management, vol. 58, no. 5, pp. 871-892, 2020.

[70] K. A. Morrison, H. H. Robbins, and D. G. Rose, "Operationalizing culturally relevant pedagogy: a synthesis of classroom-based research," Equity \& Excellence in Education, vol. 41, no. 4, pp. 433-452, 2008.

[71] A. H. Ritonga, M. E. Widdah, and Sukarno, "The role of science literacy based Ta'lim andragogy as an alternative media in strengthening covid-19 awareness," Advances in Social Science, Education and Humanities Research, vol. 566, 2021. 